\title{
O uso variável do modo subjuntivo/indicativo em orações completivas: Análise contrastiva entre o Ceará e Santa Catarina
}

The variable use of subjunctive/indicative mood in sentences completive: Contrastive analyses between Ceará and Santa Catarina

\author{
Hebe Macedo de Carvalho
}

Universidade Federal do Ceará - UFC- Fortaleza - Ceará - Brasil

\section{Tatiana Schwochow Pimpão}

Universidade Federal do Rio Grande- ILA/FURG-Rio Grande - Rio Grande do Sul - Brasil

\begin{abstract}
Resumo: Com base nos pressupostos metodológicos da Sociolinguística Comparativa (TAGLIAMONTE, 2003), confrontamos resultados de pesquisas acerca do uso variável do presente do modo subjuntivo em orações completivas em dados de fala do Ceará (Cariri e Fortaleza) e de Santa Catarina (Florianópolis e Lages) do Brasil. Em termos gerais, resultados percentuais para verbos não-factivos volitivos não diferem entre as quatro localidades, evidenciando um contexto de uso preferencial do presente do subjuntivo. De outra forma, verbos indiferentes de opinião apresentam variação relativamente equilibrada no Nordeste; no Sul, o contexto mostra-se sensível ao uso do indicativo.
\end{abstract}

Palavras-chave: Subjuntivo. Variação. Comparação. Sociolinguística

Abstract: Based on the methodological presuppositions of Comparative Sociolinguistics (TAGLIAMONTE, 2003), we confront results of research on the variable use of the subjunctive mood in complement clauses in spoken data from Ceará (Cariri and Fortaleza) and from Santa Catarina (Florianópolis and Lages) of Brazil. In general, percentage results for non-volitional factive verbs do not differ among the four locations, showing a preferential context of use of the present subjunctive. Otherwise, indifferent verbs of opinion have relatively balanced variation in the Northeast; in the South, the context shows to be responsive to the use of indicative.

Keywords: Subjunctive. Variation. Comparison. Sociolinguistics 


\section{Introdução}

Diversos estudos de inspiração sociolinguística (POPLACK, 1992; ROCHA, 1997; FAGUNDES, 2007; CARVALHO, 2007; PIMPÃO, 1999; 2012; SANTOS, 2005; MEIRA, 2006; OLIVEIRA, 2007; BARBOSA, 2013; SANTOS, 2014; AMORIM, 2015ํ) têm se voltado para a investigação da alternância das formas do indicativo e do subjuntivo em contexto de orações completivas. Esses estudos investigam os possíveis condicionadores da alternância em dados, em geral, de língua falada e têm demonstrado que o tipo de verbo da oração matriz assume um papel importante quando se estuda esse fenômeno em orações completivas, não desmerecendo, contudo, outros fatores de natureza linguística e/ou social que podem operar sobre esse uso linguístico.

A alternância das formas do indicativo e subjuntivo em orações completivas não é novidade para os estudos linguísticos. A Gramática Tradicional (BECHARA, 1999; CUNHA; CINTRA, 1985) prevê essa alternância modal em orações completivas, como decorrente do tipo de verbo da oração matriz. Em geral, para a tradição gramatical, verbos como crer, acreditar, pensar, por exemplo, podem selecionar tanto $\mathrm{o}$ indicativo quanto $\mathrm{o}$ subjuntivo na oração encaixada, sinalizando um determinado valor modal: indicativo, certeza; subjuntivo, incerteza. Já verbos como querer, desejar são apresentados como verbos que selecionam necessariamente a forma do subjuntivo na oração encaixada.

O objetivo deste estudo é, portanto, apresentar resultados de análises variacionistas do presente do subjuntivo em alternância com o presente do indicativo na fala do Português do Brasil com vistas a oferecer comparação do fenômeno quanto à variável carga semântica do verbo da oração matriz. Os dados foram coletados de entrevistas, conduzidas nos moldes labovianos, de falantes do Ceará e de Santa Catarina. Para a análise dos dados do Ceará, foram consultados

\footnotetext{
1 Os estudos contemplam diferentes tempos do subjuntivo e contextos linguísticos de análise.

2 Mais informações sobre o Banco de dados, acessar o link: http://www.profala.ufc.br/ - projeto O Português falado no Ceará.

3 Para informações mais detalhadas acerca da constituição e organização do Banco VARSUL, acessar www.varsul.org.br..
}

dois bancos de dados: Norpofor - Norma Oral do Português Popular de Fortaleza (ARAÚJO, 2011) para a cidade de Fortaleza, capital do estado, e o Português falado no Ceará, subprojeto do Profala ${ }^{2}$, que armazena dados do Cariri Cearense, região situada no sul do estado. Para a análise dos dados de Santa Catarina, foram consultadas entrevistas de Florianópolis (capital do estado) e de Lages (cidade do planalto catarinense), armazenadas no Banco de Dados do Projeto VARSUL ${ }^{3}$ (Variação Linguística na Região Sul do Brasil).

O estudo parte da observação de que, na variedade falada do Português do Brasil, o indicativo (1) pode aparecer em contextos para os quais o subjuntivo (2) é prescrito em orações completivas introduzidas pela partícula que, ilustrados a seguir com o verbo não-factivo volitivo querer.

(1) Todo mundo diz que é pra mim mudar que eu sou muito assim é ai como é que eu posso te dizer, eu não queria mudar porque eu sou eu, eu sou os outros, eu não sou o que eles QUEREM QUE eu SOU, eu não tenho que ser o que eles querem. (FLP 05, L1425) ${ }^{4}$

(2) Ele não QUER QUE nenhuma criança VOLTE pra casa. (LGS 01, L918)

Também foram controlados contextos de fala em que o subjuntivo (3) é prescrito em alternância com o indicativo (4), conforme ilustrado a seguir com o verbo pensar.

(3) Eu CREIO que ESTEJA ouvindo. Creio que isso vai acontecer um dia. (Inq36 - norpofor)

(4) Eu ACHO que toda menina PENSA né? em ter sua família. (Inq70- norporfor) $)^{5}$.

São duas as questões propostas neste trabalho: (i) Qual a atuação da carga semântica do verbo matriz na alternância subjuntivo/indicativo nas amostras investigadas? e (ii) Qual a tendência de uso do subjuntivo, em termos de frequência, no nordeste e no sul do país?

\footnotetext{
4 O código entre parênteses indica a cidade (FLP para Florianópolis e LGS - Lages), seguida pelo número da entrevista e pelo número da linha do dado.

5 O código entre parênteses indica o número do inquérito no banco de dados Norpofor.
} 
A análise a ser empreendida tem como pressupostos a Teoria da Variação e Mudança Linguística (LABOV, [1972] 2008; 2001) e a Sociolinguística Comparativa (TAGLIAMONTE, 2003), que concebem a língua como um sistema heterogêneo, dinâmico, passível de variação. Buscam descrever a língua em função de fatores linguísticos e sociais por entender o sistema linguístico motivado por esses fatores, sendo a variação inerente nas línguas humanas. Nesses termos, a variável linguística consiste numa representação abstrata da variação realizada por duas ou mais variantes (MEYERHOFF, 2006 , p. 8). A realização das variantes pressupõe o mesmo significado referencial. Em outras palavras, referem-se ao mesmo estado de coisas em um mesmo contexto e têm o "mesmo valor de verdade" nos termos propostos por LABOV (1978).

Este estudo está organizado em seis seções principais, a saber: na primeira, temos esta breve introdução; na segunda, comentamos alguns estudos já realizados no Brasil, abordando a variação no subjuntivo e a carga semântica do verbo da oração matriz; na terceira, apresentamos, sucintamente, os princípios que regem a Teoria da Variação e da Mudança Linguística e a Sociolinguística Comparativa; na quarta, descrevemos a metodologia utilizada na pesquisa; na quinta seção, apresentamos os resultados e os interpretamos; e, na sexta seção, finalizamos com as considerações finais.

\section{Estudos linguísticos sobre a alternância dos modos verbais em português}

Perini (2010), ao descrever sobre o modo verbal em orações complexas, ressalta que essa forma verbal pode ser governada por determinados verbos e por grupos de conectivos, e salienta que, no Português do Brasil, pode haver variação regional no uso da alternância subjuntivo/indicativo, porém o mapeamento desses fenômenos ainda está por ser feito. Deixa claro que, no Nordeste, os usos do PB são um tanto mais próximos dos da língua escrita, portanto mais conservadores. Estudos com dados de língua falada em algumas regiões do Brasil têm demonstrado que o Nordeste preserva mais o subjuntivo em orações substantivas do que o Sudeste (OLIVEIRA, 2007; BARBOSA, 2013). Barbosa (2013), ao comparar dados de Vitória-ES com dados de Fortaleza (CARVALHO, 2007), constata que o Nordeste apresentou o favorecimento quase categórico (97\% de subjuntivo no Cariri) em relação ao Sudeste (79\% na fala de Vitória). A autora afirma que a entrada da forma indicativa nesta região é mais acentuada do que no Nordeste.

Com relação aos trabalhos realizados com amostras do português do Brasil, destacamos a pesquisa conduzida por Rocha (1997) com dados do Rio de Janeiro e de Brasília, que tem como referência o estudo de Pereira (1974), essencialmente no que se refere à categorização dos verbos quanto à carga semântica do verbo da oração principal. Conclui Rocha (1997) que verbos não-factivos não-volitivos (deixar, pedir, temer), verbos não-factivos volitivos (esperar, preferir, querer), verbos bicondicionais (duvidar, ser possível) e verbos implicativos negativos (impedir) constituem contextos preferenciais de uso do subjuntivo, diferentemente do que ocorre com verbos indiferentes de opinião/suposição (achar, acreditar, imaginar, pensar). Carvalho (2007), com dados do Cariri, também constata a preferência do subjuntivo sob o escopo de verbos não-factivos volitivos. Analisando dados de fala do Rio de Janeiro e do noroeste de São Paulo, Santos (2005) segue a categorização controlada por Rocha (1997) e conclui que verbos implicativos negativos, verbos não-factivos não-volitivos e verbos não-factivos volitivos promovem o uso do subjuntivo em detrimento dos verbos indiferentes de opinião, que inibem esse modo verbal.

Oliveira (2007), ao estudar dados de João Pessoa, apoia-se na categorização de Rocha (1997) e observa que os verbos não-factivos não-volitivos e os verbos não-factivos volitivos constituem um ambiente propício ao uso do subjuntivo, sendo desfavoráveis os contextos de verbos indiferentes de opinião e suposição, verbos indiferentes de suposição (parecer) e verbos indiferentes de opinião (achar). Tendo como referência Rocha (1997) e os resultados alcançados 
nos demais estudos (SANTOS, 2005; OLIVEIRA, 2007), Pimpão (2012) controla a mesma variável em dados de fala de informantes de Florianópolis e de Lages. Como resultado, constata a preferência do subjuntivo pelos verbos bicondicionais, implicativos e não-factivos volitivos e a preferência do indicativo sob o escopo de verbos indiferentes de opinião.

Barbosa (2013), na pesquisa com dados de fala de Vitória, igualmente ancora-se na proposta de Rocha (1997) e observa que o subjuntivo é mais frequente quando sob o escopo de verbos não-factivos nãovolitivos e de verbos não-factivos volitivos, e menos usual quando sob o escopo de verbos indiferentes de opinião (achar) e de verbos factivos não-emotivos nãoavaliativos (saber).

Outras pesquisas que controlam, de alguma forma, o tipo de verbo da oração matriz evidenciam resultados convergentes para a preferência do subjuntivo sob o escopo de verbos volitivos (esperar, desejar, querer) e para sua inibição sob o escopo de verbos de cognição/opinião (acreditar, crer, pensar): Pimpão (1999) em Florianópolis, Meira (2006) em comunidades afro-brasileiras, Vieira (2007) em Natal, Santos (2014) em São Paulo e São Luís e Amorim (2015) em Vitória da Conquista. Fagundes (2007) trata, de certa forma, desses valores ao denominar verbos deônticos e verbos epistêmicos, sendo o modo subjuntivo frequente sob o escopo de ambos em dados de fala das quatro cidades do Paraná que compõem o Banco VARSUL (Curitiba, Irati, Londrina e Pato Branco).

\section{Pressupostos teóricos}

A Sociolinguística Quantitativa, introduzida no Brasil na década de 1970, tem, desde então, apresentado um volume expressivo de pesquisas de diversos fenômenos variáveis, contribuindo com um maior conhecimento do português brasileiro. Somamse a isso, estudos recentes objetivando uma análise comparativa em diferentes variedades brasileiras,

${ }^{6}$ Comparison has always been at the root of sociolinguistics. The study of language behavior from a comparative perspectivecomparative sociolinguistics-concerns the connection como propõem Martins e Abraçado (2015). mapeamento sociolinguístico do português brasileiro, já fazendo menção ao título da obra organizada pelos autores, pode ser ilustrado pela pesquisa acerca do uso variável dos pronomes nós $\mathrm{x}$ a gente e tu x você (cf. MARTINS; ABRAÇADO, 2015) e do uso variável do subjuntivo e indicativo (PIMPÃO, 2015). Esses trabalhos alinham-se à prerrogativa de Labov (2008, p.236) segundo a qual, "quanto mais se conhece de uma língua, mais se pode descobrir sobre ela".

É a busca por padrões subjacentes à variação e à mudança, que podem ser alcançados via comparação de resultados obtidos em diferentes amostras, que muito interessa à Sociolinguística Quantitativa. Como Guy (1999) aponta, muito do conhecimento de um fenômeno se perde quando análises comparativas, especialmente se pensarmos na extensão territorial do Brasil, deixam de ser realizadas.

Como bem ressalta Tagliamonte (2003, p. 552), a comparação tem sido a raiz da sociolinguística, sendo o estudo do comportamento de uma língua sob a perspectiva da sociolinguística comparativa voltado para a variação linguística entre bancos de dados ${ }^{6}$. Isto requer uma metodologia que, em primeiro lugar, permita que as diferentes influências das características linguísticas possam ser desvendadas através da análise sistemática do seu comportamento, e, segundo, que situe e explique as características linguísticas com base na comparação com traços das variedades relacionadas.

Diretamente relacionada com a Linguística História e a Sociolinguística Quantitativa, a Sociolinguística Comparativa constitui-se como uma metodologia cujo objetivo centra-se no estudo do comportamento da língua em diferentes amostras, com base em resultados fornecidos pela análise estatística.

O método comparativo aplicado à Sociolinguística, iniciado por Weinreich, Labov e Herzog (1968) a partir da assunção da heterogeneidade estruturada, tem sido de grande

(relationship) of linguistic variation in one body of materials to another. 
importância nos estudos diacrônicos, na busca por padrões que atravessam décadas e mesmo séculos. Traços linguísticos permanecem na língua, permitindo hipóteses explicativas para uma, pelo menos relativa, reconstrução do fenômeno linguístico investigado, bem como de sua possível trajetória de variação e/ou mudança.

Com base no método da Sociolinguística Comparativa, pretendemos, neste trabalho, discutir resultados de pesquisas conduzidas no Cariri cearense (CARVALHO, 2007), Fortaleza (CARVALHO, 2014) e em Santa Catarina (PIMPÃO, 2012) acerca de do grupo de fatores que tem mostrado significativa importância nos estudos linguísticos: a carga semântica do verbo da oração matriz em contexto de orações completivas. Os resultados ainda serão comparados com resultados de pesquisas em diferentes localidades do Brasil: Rio de Janeiro e Brasília (ROCHA, 1997), Rio de Janeiro e Noroeste de São Paulo (SANTOS, 2005), João Pessoa (OLIVEIRA, 2007) e Vitória (BARBOSA, 2013). Os dados analisados foram submetidos ao pacote de programas estatísticos Goldvarb X (SANKOFF; TAGLIAMONTE; SMITH, 2005) por fornecer análise multivariada dos dados e, assim, permitir a identificação de tendências e padrões gerais da variável linguística em estudo.

Além de Santos (2014), que descreve o uso variável do subjuntivo em São Paulo/SP e São Luís/MA, outras análises contrastivas de um fenômeno variável em estados das Regiões Nordeste e Sul já foram realizadas: Tavares (2008) investigou os conectores coordenativos e, aí, daí e então nas comunidades Florianópolis/SC e de Natal/RN, e Freitag (2008) analisou os resultados dos marcadores discursivos interacionais em Florianópolis/SC e em Itabaiana/SE. Este artigo contribui com a descrição de mais um fenômeno variável no Nordeste (Fortaleza e Cariri/CE) e no Sul (Florianópolis e Lages/SC). Um agente facilitador desse processo de descrição está na constituição de recentes bancos de dados. Por outro lado, a comparação de resultados de pesquisas em termos frequenciais (frequência absoluta e relativa) não pode ignorar a metodologia aplicada à constituição das amostras.

\section{Procedimentos metodológicos}

Nesta seção, são especificadas as amostras de fala dos Bancos de Dados do Projeto Norpofor para a cidade de Fortaleza e do Projeto Português falado no Ceará para a microrregião do Cariri Cearense, na Região Nordeste e, em seguida, do Banco de Dados do Projeto VARSUL para as cidades catarinenses de Florianópolis e Lages, na Região Sul. Na última subseção, a variável linguística é descrita.

\subsection{NORPOFOR - Fortaleza}

Parte do projeto $A$ constituição do corpus do português oral não-padrão de Fortaleza, sediado na Universidade Estadual do Ceará (UECE), o Norpofor é um banco de dados coletado no período de agosto de 2003 a julho de 2006, com 197 informantes estratificados em sexo, faixa etária, escolaridade e tipo de registro (ARAÚJO, 2011). O Norpofor foi desenvolvido com o objetivo de documentar e fornecer dados de língua falada nas modalidades de registro Diálogo entre Informante e Documentador (DID), Diálogo entre dois Informantes (D2) e Elocução Formal (EF) para o estudo da variedade popular do português falado em Fortaleza, seguindo o modelo do Projeto da Norma Urbana Oral Culta (NURC).

O estudo em tela considerou 24 entrevistas de informantes estratificados em sexo (12 homens e 12 mulheres), faixa etária (15 -25; 26 - 49; 50 anos em diante) e escolaridade (0 - 4 anos; 9 - 11 anos).

\subsection{O PORTUGUÊS FALADO NO CEARÁ- Cariri}

O projeto o português falado no Ceará conta com 190 entrevistas gravadas em cidades do Cariri cearense, especialmente Barbalha, Nova Olinda, Juazeiro, Várzea Alegre, Altaneira, Mauriti, Caririaçu e Brejo Santo. A microrregião do Cariri situa-se ao sul do estado do Ceará na fronteira com os estados de Pernambuco, Paraíba e Piauí do nordeste brasileiro. Uma das características dessa região é a proximidade das cidades entre si, compondo uma espécie de 
cornubação ${ }^{7}$. Nas palavras de Seraine (1972, p. 11), em todas as cidades do Cariri, as partes urbana e rural dos municípios se acham em intercâmbio permanente, se interpenetram culturalmente, de maneira contínua, sendo as feiras semanais pontos de atração dos rurículas, moradores em vilas, sítios e fazendas próximas. O autor ressalta ainda a importância histórica dessa comunidade e sua reconhecida "cultura popular" tradicional que preserva traços regionais específicos que já se perderam em outras regiões do Ceará.

Para efeito deste estudo, foram consultadas 60 entrevistas de informantes estratificados em sexo (30 homens e 30 mulheres), escolaridade (sem escolaridade, 1-4; 5-8; 9-11; mais de 11 anos de escolarização) e faixa etária (15-25; 26-49; 50 em diante).

\subsection{VARSUL - Florianópolis e Lages}

Com a aprovação do Projeto VARSUL em 1989, dá início ao processo de realização de entrevistas, que se estende de 1990 a 1995 em quatro cidades de cada estado da Região Sul (Rio Grande do Sul, Santa Catarina e Paraná). Destinado à pesquisa sociolinguística, o banco tem como objetivos armazenar e disponibilizar amostras de fala representativas das variedades linguísticas urbanas do sul do Brasil.

A estratificação social aplicada à constituição do Banco VARSUL distribuiu os informantes em sexo, idade (25-50 e acima de 50 anos), escolaridade (primário, ginásio e colegial ${ }^{8}$ ) e região/etnia. Para a presente pesquisa, interessam-nos o estado de Santa Catarina e a investigação de 24 entrevistas de Florianópolis e de 24 de Lages. Além do banco-base, encontra-se em andamento a ampliação do acervo de Florianópolis, que já inclui, além de entrevistas com informantes entre 15 e 24 anos, e gravações realizadas com universitários.

\footnotetext{
7 Conurbação (do lat. urbis, cidade) é a unificação da malha urbana de duas ou mais cidades, em consequência de seu crescimento geográfico.
}

\subsection{Variável}

Pereira (1974) é uma das primeiras autoras a considerar a distribuição do subjuntivo de acordo com o traço semântico do verbo da oração matriz. Rocha

(1997) propõe uma adaptação da categorização de Pereira (1974) a fim de investigar a atuação da carga semântica do verbo da oração matriz no uso do subjuntivo em variação com o indicativo em orações completivas, nos dados de fala do Rio de Janeiro, retirados do Programa de Estudos sobre os usos da língua (PEUL) e dados de fala de Brasília.

O controle da carga semântica do verbo da matriz tem sido adotado em diversas pesquisas (ROCHA, 1997; SANTOS, 2005; CARVALHO, 2007; OLIVEIRA, 2007; PIMPÃO, 2012; BARBOSA, 2013) com dados de orações completivas, sendo selecionada pelo Goldvarb X no uso da alternância indicativo/subjuntivo. Para a codificação dos dados, foi adotada a seguinte classificação: verbo não-factivo volitivo (querer, esperar, preferir), verbo não-factivo não-volitivo (pedir, ser necessário, deixar, temer), verbo factivo emotivo ou avaliativo (gostar, concordar), verbo bicondicional (duvidar, ser possível), implicativo negativo (impedir), verbo ou predicado indiferente de opinião e suposição (considerar, imaginar, pensar, acreditar, supor, dizer (=significar), significar), verbo ou predicado indiferente de suposição (parecer), verbo ou predicado indiferente de opinião (achar), verbo perfomativo e condicional (garantir, afirmar, ser certo), verbo factivo não-emotivo ou não-avaliativo (saber).

A análise a ser empreendida tomará como base geral essa proposta de categorização para o verbo matriz de orações completivas.

\section{Nordeste e Sul - uma análise comparativa}

A seguir, apresentamos e discutimos os resultados para cada uma das amostras, tendo em vista a carga semântica do verbo da oração matriz,

\footnotetext{
${ }^{8}$ O Ensino Primário e o Ginásio aproximam-se, respectivamente, dos atuais Ensino Fundamental I e Ensino Fundamental II. O Colegial atualmente é conhecido por Ensino Médio.
} 
categorização proposta por Rocha (1997) com base em Pereira (1974).

\subsection{Amostras NORPOFOR e Português falado no Ceará}

Os resultados da tabela 1 são referentes a Fortaleza e ao Cariri Cearense.

\begin{tabular}{|c|c|c|c|c|}
\hline \multirow{2}{*}{$\begin{array}{c}\text { CARGA } \\
\text { SEMÂNTICA } \\
\text { DO VERBO DA } \\
\text { ORAÇÃO } \\
\text { MATRIZ }\end{array}$} & \multirow{2}{*}{$\begin{array}{c}\text { FORTALEZA } \\
\text { Freq./Total }\end{array}$} & \multicolumn{3}{|c|}{ CARIRI $^{9}$} \\
\hline & & $\%$ & $\begin{array}{c}\text { Freq./T } \\
\text { otal }\end{array}$ & $\%$ \\
\hline Bicondicional & $2 / 2$ & $\begin{array}{c}100 \\
\%\end{array}$ & - & - \\
\hline Não-factivo volitivo & $18 / 18$ & $\begin{array}{c}100 \\
\%\end{array}$ & $31 / 32$ & $\begin{array}{l}97 \\
\%\end{array}$ \\
\hline $\begin{array}{l}\text { Não-factivo não- } \\
\text { volitivo }\end{array}$ & $2 / 3$ & $\begin{array}{l}67 \\
\%\end{array}$ & - & - \\
\hline $\begin{array}{l}\text { Predicado } \\
\text { indiferente de } \\
\text { opinião }\end{array}$ & $4 / 7$ & $\begin{array}{l}57 \\
\%\end{array}$ & $15 / 33$ & $\begin{array}{l}45 \\
\%\end{array}$ \\
\hline $\begin{array}{l}\text { Predicado } \\
\text { indiferente de } \\
\text { opinião 'achar' }\end{array}$ & $2 / 77$ & $3 \%$ & $21 / 173$ & $\begin{array}{l}12 \\
\%\end{array}$ \\
\hline $\begin{array}{l}\text { Factivo emotivo- } \\
\text { avaliativo }\end{array}$ & $2 / 5$ & $\begin{array}{l}40 \\
\%\end{array}$ & - & - \\
\hline $\begin{array}{l}\text { Verbo Dicendit } \\
\text { (dizer, contar) }\end{array}$ & - & - & $2 / 17$ & $\begin{array}{l}12 \\
\%\end{array}$ \\
\hline $\begin{array}{ll}\begin{array}{l}\text { Verbo } \\
\text { (saber) }\end{array} & \text { factivo }\end{array}$ & - & - & $1 / 31$ & $3 \%$ \\
\hline$\overline{\text { TOTAL }}$ & $30 / 112$ & $\begin{array}{l}27 \\
\%\end{array}$ & $70 / 286$ & $\begin{array}{l}24 \\
\%\end{array}$ \\
\hline
\end{tabular}

Tabela 1 - Atuação da carga semântica do verbo da oração matriz no uso do presente do modo subjuntivo em orações substantivas

Conforme demonstra a tabela, o presente do subjuntivo é favorecido, apesar de pouquíssimos dados, com verbos bicondicionais e com verbos nãofactivos volitivos (querer, desejar, preferir). Verbos não-factivos volitivos são favorecedores do presente do subjuntivo tanto em Fortaleza (100\%) quanto no Cariri (97\%).
(5) No dia de sábado eu ia deixar o dinheiro na padaria e ela dizia: QUER que eu VÁ? Eu digo: Se você quiser ir vá se não quiser... (Inq 19 - Norpofor).

Predicados indiferentes de opinião (crer, acreditar) apresentam percentuais diferentes em Fortaleza (57\%) e no Cariri (45\%), esses são os ambientes previstos inclusive pela tradução como como área de alternância entre as formas indicativa e subjuntiva. Com o verbo indiferente de opinião achar, os resultados de Fortaleza e do Cariri, apesar de apenas duas ocorrências de achar com subjuntivo na encaixada na amostra de Fortaleza, se distanciam: 3\% de presente do subjuntivo em Fortaleza e $12 \%$ no Cariri. As 2 ocorrências do presente do subjuntivo em orações com o verbo matriz achar, em Fortaleza, foram com o verbo ser na oração encaixada, conforme ilustram os exemplos.

(6) É como a minha prima também, ela mal conheceu o pai dela. Ela já viajou lá pra casa do pai dela e tudo, mas (assim) não é um sentimento de pai e filha... Eu ACHO que SEJA assim (Inq73 Norporfor).

(7) Quer dizer que um adulto que mata é mais responsável que garoto de dezesseis ano? Eu não ACHO que SEJA (Inq 82 - Norpofor).

As outras 77 ocorrências com achar apresentaram verbos encaixados no presente do indicativo, o que indicia processo de gramaticalização dessas estruturas já atestado nos dados de Florianópolis e Lages, por exemplo. Para Galvão (1999), o verbo achar está deixando de manifestar, gradativamente, as propriedades de verbo pleno, decategorizando-se. A autora explicita que à medida que apresentam um caráter modalizador mais forte, os tipos de achar tendem a não manifestar variabilidade modo-temporal.

\footnotetext{
${ }^{9}$ A tabela com os resultados do Cariri é adaptada de Carvalho (2007, p. 91).
}

10 Verbos dicendi e factivos não foram controlados na amostra de Fortaleza. 


\subsection{Amostras VARSUL}

Os resultados da tabela 2 são referentes a Florianópolis e Lages.

Tabela 2 - Atuação da carga semântica do verbo da oração matriz no uso do presente do modo subjuntivo em orações substantivas (adaptado de PIMPÃO, 2012, p. 249)

\begin{tabular}{|c|c|c|c|c|}
\hline \multirow{2}{*}{$\begin{array}{c}\text { CARGA } \\
\text { SEMÂNTIC } \\
\text { A DO } \\
\text { VERBO DA } \\
\text { ORAÇÃO } \\
\text { MATRIZ }\end{array}$} & \multicolumn{2}{|c|}{$\begin{array}{c}\text { FLORIANÓPOLI } \\
\text { S }\end{array}$} & \multicolumn{2}{|c|}{ LAGES } \\
\hline & Freq./Total & $\%$ & $\begin{array}{c}\text { Freq./Tota } \\
\text { I }\end{array}$ & $\%$ \\
\hline Bicondicional & $06 / 06$ & 100 & $08 / 08$ & $\begin{array}{c}10 \\
0\end{array}$ \\
\hline Implicativo & $03 / 03$ & 100 & $07 / 07$ & $\begin{array}{c}10 \\
0\end{array}$ \\
\hline $\begin{array}{l}\text { Bicondicional } \\
\text { negativo }\end{array}$ & $02 / 02$ & 100 & - & - \\
\hline $\begin{array}{l}\text { Não-factivo } \\
\text { volitivo }\end{array}$ & $21 / 23$ & 91 & $24 / 25$ & 96 \\
\hline $\begin{array}{l}\text { Não-factivo } \\
\text { não-volitivo }\end{array}$ & $07 / 13$ & 53 & $12 / 14$ & 85 \\
\hline Performativo & $05 / 10$ & 50 & - & - \\
\hline $\begin{array}{l}\text { Predicado } \\
\text { indiferente } \\
\text { de opinião }\end{array}$ & $05 / 16$ & 31 & $01 / 17$ & 05 \\
\hline $\begin{array}{l}\text { Factivo } \\
\text { emotivo- } \\
\text { avaliativo }\end{array}$ & $01 / 06$ & 16 & $06 / 07$ & 85 \\
\hline$\overline{\text { TOTAL }}$ & $50 / 79$ & 63 & $58 / 78$ & 74 \\
\hline
\end{tabular}

De acordo com a tabela 2, e a despeito do número de dados, o presente do subjuntivo mostra-se categórico sob o escopo de verbos bicondicionais e implicativos para os dados de ambas as cidades e categórico sob o escopo de verbos bicondicionais negativos para Florianópolis. Para os verbos nãofactivos volitivos (desejar, esperar, exigir, preferir, pretender, querer), os percentuais são bastante próximos para os dados de Florianópolis (91\%) e

\footnotetext{
${ }^{11}$ Exemplo: NÃO VOU DIZER pra ti QUE ele ESTÁ ganhando mal, mas também não ganha bem pra gente viver bem. (FLP 11, L317)
}

Lages (96\%) (cf. ROCHA, 1997; SANTOS; 2005; OLIVEIRA, 2007; BARBOSA, 2013). Diferentemente, no caso dos verbos não-factivos não-volitivos (deixar, pedir, permitir, precisar), o percentual distancia-se: Florianópolis (53\%) e Lages (85\%). A explicação para essa diferença parecer residir na frequência do verbo deixar em Florianópolis: das seis ocorrências, cinco conduzem ao indicativo.

Os verbos performativos (dizer, ter debatido) somente aparecem na fala de informantes florianopolitanos, com o percentual de $50 \%$ para o presente do subjuntivo. Das sete ocorrências com o verbo dizer negado ${ }^{11}$, cinco são seguidas de indicativo. Com os verbos indiferentes de opinião, o percentual de uso do subjuntivo é baixo ainda que mais produtivo em Florianópolis (31\%) do que em Lages (05\%) (cf. ROCHA, 1997; SANTOS, 2005; OLIVEIRA, 2007; BARBOSA, 2013). Por fim, os verbos emotivosavaliativos atingem percentuais diferentes: Florianópolis com 16\% (verbos concordar, estar bem) e Lages com 85\% (verbos gostar, ser pena, ser bom).

\subsection{Resultados no Nordeste e no Sul do Brasil}

A tabela seguinte apresenta os percentuais de uso do presente do subjuntivo no Nordeste e no Sul do Brasil para efeito de comparação entre as comunidades de fala em estudo.

Tabela 3 - Atuação da carga semântica do verbo da oração matriz no uso do presente do modo subjuntivo em orações substantivas nas Regiões Nordeste e Sul

\begin{tabular}{|c|c|c|c|c|}
\hline VARIÁVEL & NORD & STE & SUL & \\
\hline $\begin{array}{c}\text { Carga } \\
\text { semântica do } \\
\text { verbo da oração } \\
\text { matriz }\end{array}$ & $\begin{array}{c}\text { Fortale } \\
\text { za }\end{array}$ & $\begin{array}{c}\text { Cari } \\
\text { ri }\end{array}$ & $\begin{array}{c}\text { Florianópo } \\
\text { lis }\end{array}$ & $\begin{array}{l}\text { Lage } \\
\mathbf{s}\end{array}$ \\
\hline Bicondicional & $100 \%$ & - & $100 \%$ & $\begin{array}{c}100 \\
\%\end{array}$ \\
\hline Implicativo & - & - & $100 \%$ & $\begin{array}{c}100 \\
\%\end{array}$ \\
\hline $\begin{array}{l}\text { Bicondicional } \\
\text { negativo } \\
\end{array}$ & - & - & $100 \%$ & - \\
\hline Não-factivo volitivo & $100 \%$ & $97 \%$ & $91 \%$ & $96 \%$ \\
\hline $\begin{array}{l}\text { Não-factivo não- } \\
\text { volitivo }\end{array}$ & $67 \%$ & - & $53 \%$ & $85 \%$ \\
\hline $\begin{array}{l}\text { Verbo Dicendi } \\
\text { (dizer, } \\
\text { contar)/Performativ } \\
0^{12}\end{array}$ & - & $12 \%$ & $50 \%$ & - \\
\hline
\end{tabular}

12 Nos dados do Nordeste, o fator é nomeado Verbo Dicendi (dizer, contar); nos dados do Sul, o fator é designado 


\begin{tabular}{l|c|c|c|c}
\hline $\begin{array}{l}\text { Indiferente de } \\
\text { spinião }\end{array}$ & $57 \%$ & $45 \%$ & $31 \%$ & $05 \%$ \\
\hline $\begin{array}{l}\text { Factivo emotivo- } \\
\text { avaliativo }\end{array}$ & $40 \%$ & - & $16 \%$ & $85 \%$ \\
$\begin{array}{l}\text { Predicado de } \\
\text { indiferente de dectivo } \\
\text { opinião 'achar'13 }\end{array}$ & - & $3 \%$ & - & - \\
$\begin{array}{l}\text { Verbo factio } \\
\text { (saber) }\end{array}$ & $\mathbf{2 7 \%}$ & $\mathbf{2 4 \%}$ & $\mathbf{6 3 \%}$ & $\mathbf{7 4 \%}$ \\
\hline TOTAL &
\end{tabular}

De imediato, destacam-se os resultados percentuais gerais devido à distância entre as regiões: o Nordeste com uma baixa produtividade de subjuntivo ( $27 \%$ e $24 \%$ ) e o sul, ao contrário, com uma maior produtividade desse modo verbal (63\% e 74\%). É preciso, no entanto, observar que ocorrências com os verbos achar e saber não foram controladas na investigação empreendida com dados da Região Sul (cf. nota de rodapé 14). Retirando esses verbos, o presente do subjuntivo atinge um percentual de $80 \%$ (28/35) em Fortaleza e de 59\% no Cariri (48/82). Esses resultados, associados aos do sul do país, sinalizam uma configuração interessante: em termos percentuais, Fortaleza aproxima-se de Lages $(80 \% \mathrm{e}$ $74 \%$ ) e o Cariri de Florianópolis (59\% e 63\%).

Analisando Fortaleza (80\%) e Lages (74\%), podemos atribuir o percentual elevado de subjuntivo a dois fatores. Em primeiro lugar, o tipo de verbo mais frequente nos dados de Fortaleza é o verbo não-factivo volitivo, que, conforme pesquisas, constitui um contexto propício ao uso do subjuntivo (ROCHA, 1997; SANTOS, 2005; OLIVEIRA, 2007; BARBOSA, 2013). Em segundo, em Lages, o subjuntivo tende a ser mais frequente em praticamente todos os tipos de verbo considerados na análise. Seguem exemplos de orações matrizes com verbo não-factivo volitivo favorecedor do subjuntivo.

Analisando o Cariri (59\%) e Florianópolis (63\%), podemos igualmente considerar dois fatores. Primeiramente, é importante observar que, das 82 ocorrências de contexto de subjuntivo no Cariri desconsiderando os verbos achar e saber -, 33 são de

Performativo, e os verbos dizer e ter debatido são controlados. Como exemplo de uma ocorrência com verbo performativo, retomar a nota de rodapé anterior.

${ }^{13} \mathrm{O}$ verbo achar não foi controlado nas rodadas de Florianópolis e de Lages devido ao grande número de ocorrências e à baixíssima produtividade do presente do subjuntivo: e verbos indiferentes de opinião, i.e., 33\% do total. Vale lembrar que pesquisas com dados do português brasileiro identificaram esse contexto como sensível ao uso do indicativo (ROCHA, 1997; SANTOS, 2005; OLIVEIRA, 2007; BARBOSA, 2013). Nesse sentido, além desse tipo de verbo privilegiar o indicativo (cf. tabela 3), 33\% dos dados do Cariri estão nesse contexto. Pensamos que o percentual mais baixo de subjuntivo no Cariri (59\%) esteja sendo afetado por esse fator. Em segundo, em Florianópolis, os contextos de uso do subjuntivo apresentam, de forma geral, uma preferência pelo presente do indicativo. Parece-nos que Florianópolis possa, de fato, ser a localidade com uma tendência mais saliente para a inibição do subjuntivo, excetuando, certamente, o contexto de verbos não-factivos volitivos.

Como síntese de análise, em termos gerais, resultados percentuais para verbos não-factivos volitivos não diferem entre as quatro localidades, evidenciando um contexto de uso preferencial do presente do subjuntivo. De outra forma, verbos indiferentes de opinião apresentam variação relativamente equilibrada no Nordeste (Fortaleza e Cariri); no Sul (Florianópolis e Lages), o contexto mostra-se sensível ao uso do indicativo como mostra o gráfico, a seguir.

Florianópolis, todos os 136 dados estão no indicativo; em Lages, dos 148 dados, apenas 6 estão no subjuntivo.

${ }^{14} \mathrm{O}$ verbo saber não foi controlado nas rodadas de Florianópolis e de Lages por ser de uso categórico de indicativo. 
Gráfico 1: Distribuição das frequências da alternância subjuntivo/indicativo em orações completivas em função dos verbos matrizes não-factivos volitivos e verbos indiferentes de opinião em Fortaleza, Cariri, Florianópolis e Lages.

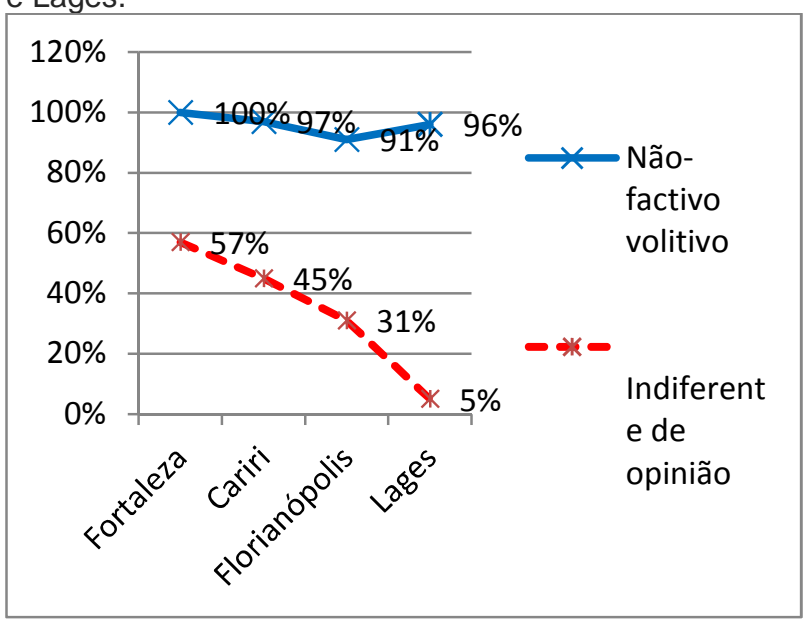

Retomando os resultados apresentados na tabela 3 quanto ao verbo achar, importa destacar o percentual mais elevado de subjuntivo no Cariri (12\%) em relação a Fortaleza (3\%). Conforme mencionado, em Florianópolis, o indicativo é categórico sob o escopo desse verbo e, em Lages, o subjuntivo ocorre em apenas 4\% dos dados. Parece-nos que o Cariri preserva mais o presente do subjuntivo, especialmente se considerarmos os casos com o verbo achar e os verbos indiferentes de opinião.

\section{Considerações finais}

A análise comparativa dos dados de variação entre presente do subjuntivo e presente do indicativo nas duas regiões do país permitiu a proposição de alguma generalização a despeito de alguns obstáculos que se interpõem: constituição de cada amostra investigada, perfil dos informantes, fatores controlados em cada uma das amostras, número de ocorrências. Ressalvas observadas, a análise comparativa permitiu identificar padrões de variação nas variedades investigadas, especialmente quanto à forte associação entre subjuntivo e verbos não-factivos volitivos. Em predicados indiferentes de opinião, ambiente de alternância já previsto inclusive pelas descrições das gramáticas tradicionais, o Nordeste (Fortaleza $57 \% /$ Cariri - 45\%) parece conservar mais o presente do subjuntivo do que o Sul (Florianópolis - 31\%/Lages
- 05\%). Esses resultados parecem confirmar a proposição de Perini (2010) acerca do uso mais produtivo do subjuntivo na Região Nordeste.

\section{Referências}

AMORIM, Vânia Raquel Santos. A gramaticalização do subjuntivo: Um estudo do português popular. 2015. 150f. Dissertação (Mestrado em Linguística). Universidade Estadual do Sudoeste da Bahia, Vitória da Conquista, 2015.

ARAÚJO, Aluiza Alves de. O projeto norma oral do português popular de Fortaleza. Cadernos do CNLF, Vol. XV, № 5, t. 1. Rio de Janeiro: CiFEFiL, 2011.

CUNHA, C.; CINTRA, Lindley. F. Nova gramática do português contemporâneo. Rio de Janeiro: Nova Fronteira, 1985.

BARBOSA, Astrid Franco. Alternância de formas indicativas e subjuntivas na fala de Vitória (ES). 2013. 213f. Dissertação (Mestrado em Linguística) - Universidade Federal do Espírito Santo, Vitória, 2013.

BECHARA, E. Moderna gramática portuguesa. 37. ed. rev. e ampl. Rio de Janeiro: Lucerna, 1999.

CARVALHO, Hebe Macedo de. A alternância indicativo/subjuntivo nas orações substantivas em função dos tempos verbais presente $e$ imperfeito na língua falada do Cariri. 2007. $158 f$. Tese (Doutorado em Linguística) - Departamento de Letras Vernáculas, Universidade Federal do Ceará, Fortaleza, 2007.

Alternância das formas subjuntivo e indicativa na fala do Ceará: uma análise variacionista. Linha D'Água (Online), São Paulo, v. 27, n. 1, p. 169-190, jun. 2014.

FAGUNDES, Edson Domingos. As ocorrências do modo subjuntivo nas entrevistas do VARSUL no estado do Paraná e as possibilidades de variação com o modo indicativo. 2007. 220f. Tese (Doutorado em Letras) - Ciências Humanas, Letras e Artes, Universidade Federal do Paraná, Curitiba, 2007.

FREITAG, Raquel Meister Ko. Marcadores discursivos interacionais na fala de Itabaiana/SE. Revista do GELNE, 10(1), p. 21-32, 2008.

GUY, Gregory. Notas do curso Sociolinguística Comparativa, ministrado de 22/02 a 05/03, na UFSC, por ocasião do XIV Instituto Linguístico da ABRALIN, 1999. 
LABOV, William. Padrões sociolinguísticos. Trad. Marcos Bagno, Maria Marta Pereira Scherre e Caroline R. Cardoso. São Paulo: Parábola, 2008[1972].

Principles of linguistics change: Social factors. Malden, Massachussets-USA: Blackwell, 2001.

MARTINS, Marco Antonio; ABRAÇADO, Jussara. Mapeamento sociolinguístico do português brasileiro. São Paulo: Contexto, 2015.

MEIRA, Vivian. O uso do modo subjuntivo em orações relativas e completivas no português afrobrasileiro. 2006. 317f. Dissertação (Mestrado em Letras e Linguística) - Instituto de Letras, Universidade Federal da Bahia, Salvador, 2006.

MEYERHOFF, Miriam. Introducing sociolinguistics. London and New York: Routledge, 2006.

OLIVEIRA, Maria do Carmo de. O uso do modo verbal em estruturas de complementação no português do Brasil. 2007. 155f. Dissertação (Mestrado em Linguística) - Instituto de Letras, Universidade de Brasília, Brasília, 2007.

PEREIRA, Maria Angela Botelho. Aspectos da oposição modal indicativo/subjuntivo no português contemporâneo. 1974. 265f. Dissertação (Mestrado em Língua Portuguesa) Universidade Federal do Rio de Janeiro, Rio de Janeiro, 1974.

PERINI, Mário. Gramática do português brasileiro. São Paulo: Parábola, 2010.

PIMPÃO, Tatiana Schwochow. Mapeamento do uso variável do modo subjuntivo no português do Brasil. Working Papers em Linguística, 16(1), 120-141, Florianópolis, jan/jul, 2015.

Uso variável do presente do modo subjuntivo: Uma análise de amostras de fala e escrita das cidades de Florianópolis e Lages nos séculos XIX e $X X$. 2012. 350f. Tese (Doutorado em Linguística) - Centro de Comunicação e Expressão, Universidade Federal de Santa Catarina, Florianópolis, 2012.

Variação no presente do modo subjuntivo: Uma abordagem discursivo-pragmática. 1999. 129f. Dissertação (Mestrado em Linguística) Centro de Comunicação e Expressão, Universidade Federal de Santa Catarina, Florianópolis, 1999.

ROCHA, Rosa Cecília Freire da. A alternância indicativo/subjuntivo nas orações subordinadas substantivas em português. 1997. $125 \mathrm{f}$.
Dissertação (Mestrado em Linguística) Departamento de Linguística, Línguas Clássicas e Vernáculas, Universidade de Brasília, Brasília, 1997.

SANTOS, Wendel Silva dos. A morfologia do indicativo na expressão do modo subjuntivo em São Paulo e São Luís. 2014. 141f. Dissertação (Mestrado e Linguística) - Departamento de Linguística, Universidade de São Paulo, São Paulo, 2014.

SANTOS, Regina Marques Alves dos. O uso variável do modo subjuntivo em estruturas complexas. 2005. 170f. Dissertação (Mestrado em Estudos Linguísticos) - Instituto de Biociências, Letras e Ciências Exatas, Universidade Estadual Paulista, São José do Rio Preto, 2005.

SANKOFF, David; TAGLIAMONTE, Sali A.; SMITH, E. Goldvarb X - A multivariate analysis application. Toronto: Department of Linguistics; Ottawa: Department of Mathematics, 2005. Disponível em:<http://individual.utoronto.ca/tagliamonte/Gol dvarb/GV_index.htm\#ref>.

SERAINE, Floriano. Introdução ao Atlas linguístico e folclórico do Cariri. In: Revista do Instituto do Ceará, 86, Fortaleza, 1972. (p.5-23).

TAGLIAMONTE, Sali. Comparative sociolinguistics. In: CHAMBERS, Jack; TRUDGILL, Peter; SHILLING-ESTES, Natalie. (Orgs.). The Handbook of Language Variation and Change. Cambridge: Blackwell, 2003, p. 729-763.

TAVARES, Maria Alice Tavares. Conectores coordenativos: condicionamentos sociais em duas comunidades de fala brasileiras. Linguística, 4(1), p. 19-37, 2008.

VIEIRA, Marta Mara Munguba. Alternância no uso dos modos indicativo e subjuntivo em orações subordinadas substantivas: Uma comparação entre o português do Brasil e o francês do Canadá. 2007. 106f. Dissertação (Mestrado em Letras) - Departamento de Letras, Universidade Federal do Rio Grande do Norte, Natal, 2007.

WEINREICH, Uriel; LABOV, William; HERZOG, Marvin. Empirical foundations for a theory of language change. In: LEHMANN, W. e MALKIEL, Y. (eds.) Directions for historical linguistics. Austin: University of Texas Press, 1968. 



\section{COMO CITAR ESSE ARTIGO}

DE CARVALHO, Hebe Macedo; PIMPÃO, Tatiana Schwochow. O USO VARIÁVEL DO MODO SUBJUNTIVO/INDICATIVO EM ORAÇÕES COMPLETIVAS: ANÁLISE CONTRASTIVA ENTRE O CEARÁ E SANTA CATARINA. Signo, Santa Cruz do Sul, v. 41, n. 71, out. 2016. ISSN 1982-2014. Disponível em: <https://online.unisc.br/seer/index.php/signo/article/view/7173>. Acesso em: doi: http://dx.doi.org/10.17058/signo.v41i71.7173. 